\title{
Erratum to: Investigating the Factor Structure of the Kessler Psychological Distress Scale in Community and Clinical Samples of the Australian Population
}

\author{
Matthew Sunderland • Alison Mahoney • Gavin Andrews
}

Published online: 2 October 2013

(C) Springer Science+Business Media New York 2013

Erratum to: J Psychopathol Behav Assess (2012) 34:253-259

DOI 10.1007/s10862-012-9276-7

The description of the third model provided on page 255 under the section 'Statistical Analyses' is incorrect. The correct sentence is provided below.

"The third model (Brooks et al. 2006) comprised of two factors with one factor loading on items associated with depression (fatigue, loss of energy, hopelessness, sad, so sad, worthlessness), whilst the other factor loading on items associated with anxiety (nervous, so nervous, restless/fidgety, so restless)." Additionally, the path diagram for Model 3 in Figure 1 is incorrect. The correct figure is provided below.

The online version of the original article can be found at http://dx.doi.org/ 10.1007/s10862-012-9276-7.

M. Sunderland $(\bowtie) \cdot$ A. Mahoney $\cdot$ G. Andrews

Clinical Research Unit for Anxiety and Depression (CRUfAD),

Level 4, O’Brien Centre, St Vincent's Hospital, 394-404 Victoria

Street, Darlinghurst, NSW, Australia

e-mail: matthews@unsw.edu.au

A. Mahoney $\cdot$ G. Andrews

St. Vincent's Hospital, Sydney, NSW, Australia

M. Sunderland · A. Mahoney $\cdot$ G. Andrews

School of Psychiatry, University of New South Wales, Sydney, NSW,

Australia 

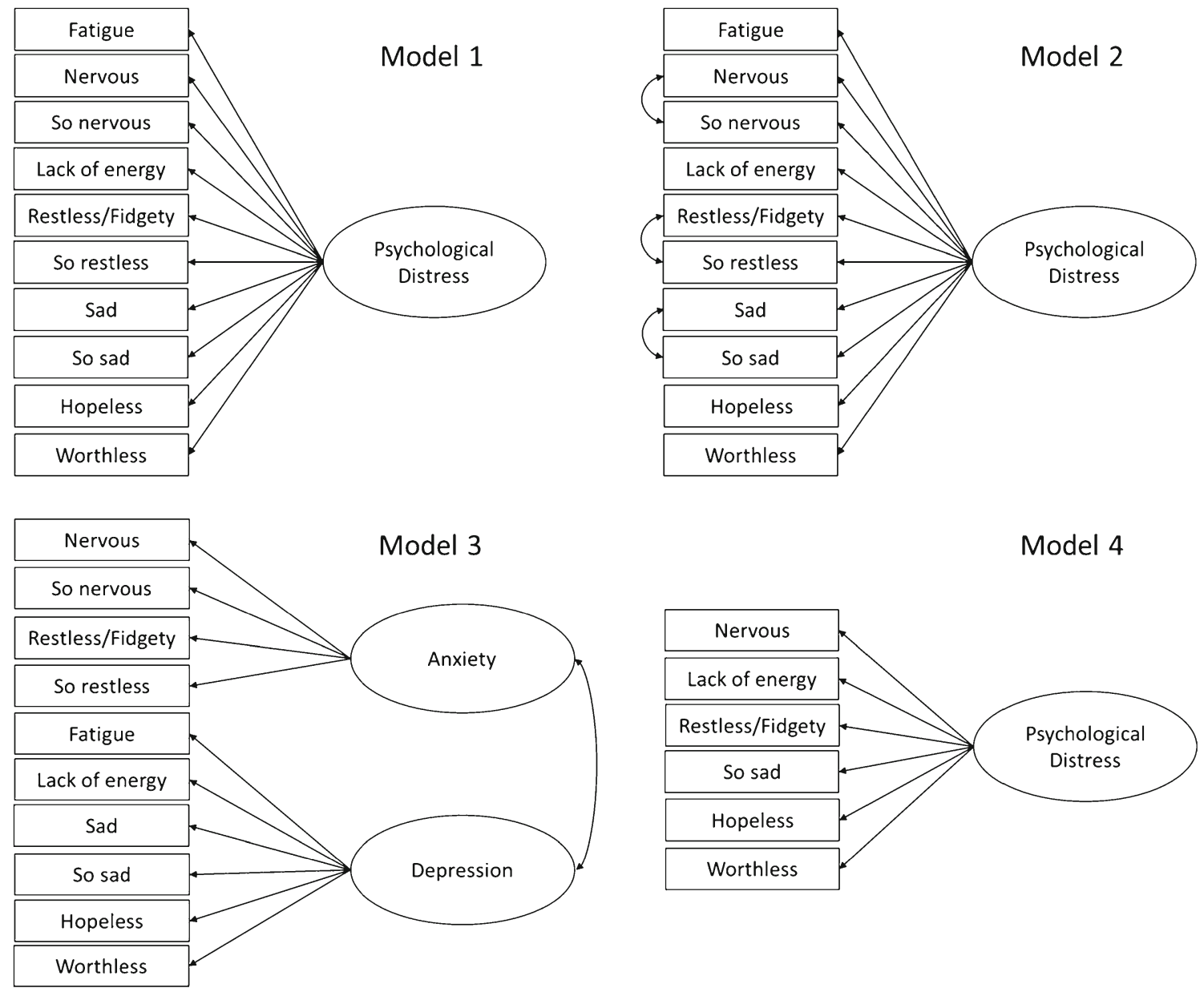

Model 4

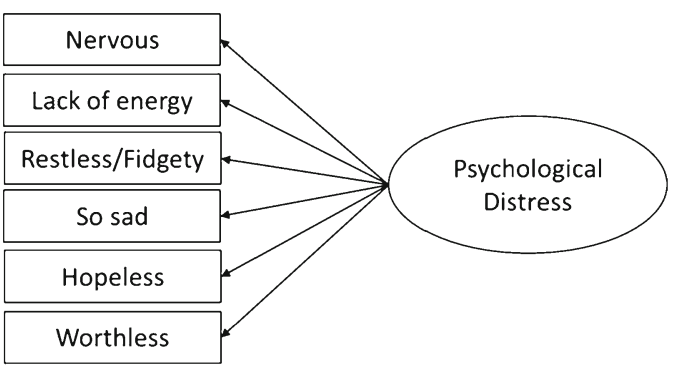

Fig. 1 Path diagrams of the four tested theoretical structure models for the Kessler psychological distress scale. 